\title{
THERMAL METALORGANIC CHEMICAL VAPOR DEPOSITION OF Ti-Si-N FILMS FOR DIFFUSION BARRIER APPLICATIÖNS
}

\author{
J. S. Custer, a) Paul Martin Smith, a) Ronald V. Jones, a) A.W. Maverick, b) \\ D. A. Roberts, c) J. A. T. Norman, c) and A. K. Hochbergc) \\ a) Sandia National Laboratories, Albuquerque, NM 87185 \\ b) Louisiana State University, Baton Rouge, LA 70803 \\ c) Schumacher, Incorporated, Carlsbad, CA 92009
}

\section{ABSTRACT}

Structurally disordered refractory ternary films such as titanium silicon nitride (Ti-Si-N) have potential as advanced diffusion barriers in future ULSI metallization schemes. Here we present results on purely thermal metalorganic chemical vapor deposition (CVD) of Ti-Si-N. At temperatures between 300 and $450^{\circ} \mathrm{C}$, tetrakis(diethylamido)titanium (TDEAT), silane, and ammonia react to grow Ti-Si-N films with Si contents of 0-20 at.\%. Typical impurity contents are $5-10$ at.\% $\mathrm{H}$ and 0.5 to 1.5 at.\% $\mathrm{C}$, with no $\mathrm{O}$ or other impurities detected in the bulk of the film. Although the film resistivity increases with increasing $\mathrm{Si}$ content, it remains below $1000 \mu \Omega$-cm for films with less than 5 at.\% Si. These films are promising candidates for advanced diffusion barriers.

\section{INTRODUCTION}

As critical dimensions for ULSI devices continue to shrink, new metallization technologies will be required. One necessity is a conformal, 10-20 nm thick diffusion barrier which is compatible with novel metals such as hot-sputtered Al, CVD Al, or Cu. Presently, sputtered TiN is the standard diffusion barrier, but the poor conformality of sputtering has led to investigations of CVD TiN diffusion barriers. Two primary chemistries have been investigated, using either $\mathrm{TiCl}_{4}$ and $\mathrm{NH}_{3}$ [1], or a Ti metalorganic precursor such as TDEAT (or the similar dimethylamido compound TDMAT) alone or with $\mathrm{NH}_{3}$ [2-4]. It is reportedly difficult, however, to produce TiN films from these metalorganic precursors with low resistivity, good conformality, and low impurity levels. Furthermore, since these TiN films are generally polycrystalline, grain-boundary diffusion will remain as a failure mechanism.

Structurally disordered refractory ternary films such as Ti-Si-N have been shown to be promising candidates for $\approx 10 \mathrm{~nm}$ diffusion barrier applications by experiments on sputtered ternary films $[5,6]$. Sputtered Ti-Si-N films are thought to be composed of nanocrystals of $\mathrm{TiN}$ in a $\mathrm{Si}_{3} \mathrm{~N}_{4}$ matrix, giving a barrier with pre-stuffed grain boundaries. 
In this paper we report on the development of a CVD process for Ti-Si-N. The process uses TDEAT, $\mathrm{SiH}_{4}$, and $\mathrm{NH}_{3}$ at temperatures from 300 to $450^{\circ} \mathrm{C}$. The film resistivity and conformality suggest that these films are attractive candidates for future ULSI diffusion barrier applications.

\section{EXPERIMENT}

The Ti-Si-N films were deposited on $150 \mathrm{~mm} \mathrm{Si}$ wafers in a Materials Research Corporation Phoenix CVD system. Silane, ammonia, and nitrogen were mixed in the showerhead and flowed down over the wafer, which is mounted on a rotatable, heated susceptor. The TDEAT was in a heated bubbler (normally $80^{\circ} \mathrm{C}$ ) and delivered seperately into the chamber to avoid pre-reactions in the showerhead. Typical precursor flow rates were 100 sccm of $\mathrm{N}_{2}$ as the carrier gas (yielding $\sim 5 \mathrm{sccm}$ TDEAT) in the bubbler, $1000 \mathrm{sccm} \mathrm{NH}$, $1000 \mathrm{sccm} \mathrm{N} \mathrm{N}_{2}$, and $<1 \mathrm{sccm} \mathrm{SiH}_{4}$. During all depositions the system pressure was maintained at 20 Torr and the wafers were rotated at $100 \mathrm{rpm}$. The deposition time was varied from 1 to 15 minutes, with 5-10 minutes being typical deposition times for the $\sim 50 \mathrm{~nm}$ thick films deposited for analysis. Thermal contact between the susceptor and wafer was enhanced by 10 Torr of He on the backside of the wafer, and the susceptor was kept at temperatures from 300 to $450^{\circ} \mathrm{C}$.

Depositions were performed on both thermal oxide and bulk Si wafers, as well as various test structures. Film compositions were measured by Rutherford backscattering spectrometry (RBS) with $3.5 \mathrm{MeV} \mathrm{He}$ and elastic recoil detection (ERD) using $28 \mathrm{MeV}$ $\mathrm{Si}^{5+}$. The films were also characterized by mass gain and resistivity. Gap fill and microstructure were investigated with scanning electron microscopy (SEM) and transmission electron microscopy (TEM), respectively.

\section{RESULTS AND DISCUSSION}

Figure 1 shows the $\mathrm{Si}$ content of films deposited under different precursor flows. It is surprising that $\mathrm{SiH}_{4}$ reacts at all at these temperatures. (Note that $\mathrm{Si}_{3} \mathrm{~N}_{4}$ cannot be deposited thermally from $\mathrm{SiH}_{4}$ and $\mathrm{NH}_{3}$ at these temperatures.) As the ratio of $\mathrm{SiH}_{4}$ to TDEAT increases, the amount of $\mathrm{Si}$ incorporated in the film increases logarithmically. The TDEAT flow rate was calculated assuming a 1 Torr vapor pressure in the bubbler at $80^{\circ} \mathrm{C}$. In addition, higher deposition temperatures result in more Si being incorporated under similar precursor flows. Because all depositions were carried out at a constant pressure (20 Torr), the total gas flow ([All] in the figure) during the deposition determines the average residence time in the reactor, which in turn affects the $\mathrm{Si}$ incorporation. As the residence time increases (total flow 
decreases), more $\mathrm{Si}$ is incorporated in the film at a given $\mathrm{SiH}_{4}$ to TDEAT ratio. The line in Fig. 1 is an extrapolation of the lower $\mathrm{SiH}_{4}$ flow data, and is meant solely to guide the eye. Because $\mathrm{SiH}_{4}$ will neither thermally decompose by itself or react with $\mathrm{NH}_{3}$ at these temperatures, it is clear that there will be an upper limit to the Si content that can be incorporated in a Ti-Si-N film.

Figure 2 shows a Ti-Si-N ternary phase diagram of the films grown using TDEAT, $\mathrm{SiH}_{4}, \mathrm{NH}_{3}$, and $\mathrm{N}_{2}$. The tie lines shown are based on the available data from temperatures above $500^{\circ} \mathrm{C}$ [7], and do not reflect the wide variations possible in $\mathrm{N}$ content for the TiN phase. These films are all clustered on the $\mathrm{N}$-rich side of the $\mathrm{Si}_{3} \mathrm{~N}_{4}$-TiN tie line. These compositions are encouraging since the most promising sputtered barriers also lie along the $\mathrm{Si}_{3} \mathrm{~N}_{4}$-TiN tie line [6]. The only impurities found in the films by RBS or ERD were hydrogen and carbon. Some surface oxygen could occasionally be detected, but, unless the deposition chemistry was too lean in $\mathrm{NH}_{3}$, no $\mathrm{O}$ was detected in the bulk of the film.

The resistivity of the film varies dramatically with the Si content, as shown in Fig. 3. Increasing the Si content exponentially increases the resistivity. At Si concentrations below 5 at.\%, the film resistivity falls below $1000 \mu \Omega-\mathrm{cm}$. Different deposition temperatures generate slightly different curves, with the minimum resistivity at a given Si content occuring for deposition temperatures of $350^{\circ} \mathrm{C}$. At temperatures above or below $350^{\circ} \mathrm{C}$, the films are richer in nitrogen and also have higher resistivities.

The step coverage of these films is very good, which is necessary for conformal coverage of high aspect ratio structures. Figure 4 shows a cross-section SEM of a $50 \mathrm{~nm}$ thick $\mathrm{Ti}_{0.46} \mathrm{Si}_{0.03} \mathrm{~N}_{0.51}$ film grown at $350^{\circ} \mathrm{C}$, which has a resistivity of under $700 \mu \Omega-\mathrm{cm}$. The film is deposited over $0.5 \mu \mathrm{m}$ trenches with an aspect ratio of 1.6 through oxide to polysilicon. The step coverage is at least $80 \%$, and the film faithfully reproduces the irregularities on the original structures.

\section{CONCLUSIONS}

We have demonstrated that purely thermal metalorganic chemical vapor deposition can produce Ti-Si-N films with low impurity contents over a wide process window. The precursors, TDEAT, $\mathrm{SiH}_{4}$, and $\mathrm{NH}_{3}$, are readily available and generally accepted. The incorporation of Si can easily be varied across a wide range (0-20 at.\%) by changing the ratios of the precursors. Although the film resistivity increases dramatically with Si content, resistivities below $1000 \mu \Omega-\mathrm{cm}$, required for diffusion barrier use, are obtained for Si contents below 5 at.\%. Films with these low silicon contents exhibit step coverages of at least $80 \%$ 
over $0.5 \mu \mathrm{m}$ trenches with aspect ratios of 1.6. It appears that CVD Ti-Si-N films may be excellent candidates for future ULSI diffusion barriers.

\section{ACKNOWLEDGEMENTS}

Sandia National Laboratories is supported by the United States Department of Energy under Contract DE-AC04-94AL85000.

\section{REFERENCES}

1. J.T. Hillman, D. Srinivas, R.F. Foster, R.J. Graham, F. Shaapur, and M.R. McCartney, in Advanced Metallization for ULSI Applications in 1993, edited by D. P. Favreau, Y. Shacham-Diamond, and Y. Horiike (Materials Research Society, Pittsburgh, PA, 1994) pp. 167-173.

2. I.J. Raaijmakers, Thin Solid Films 247, 1994, pp. 85-93.

3. R.L. Jackson, E.J. McInerney, B. Roberts, J. Strupp, A Velaga, S. Patel, and L. Halliday, in Advanced Metallization for ULSI Applications in 1994, edited by R. Blumenthal and G. Janssen (Materials Research Society, Pittsburgh, PA, 1994) pp. 223-229.

4. M. Eizenberg, K. Littau, S. Ghanayem, A. Mak, Y. Maeda, M. Chang, and A.K. Sinha, Appl. Phys. Lett. 65 (19), 1994, pp. 2416-2418; M. Danek, M. Liao, J. Tseng, K. Littau, D. Saigal, H. Zhang, R. Mosely, and M. Eizenberg, Appl. Phys. Lett. 68, 1015 (1996).

5. J.S. Reid, X. Sun, E. Kolawa, and M.-A. Nicolet, IEEE Elec. Dev. Lett. 15 (8), 1994, pp. 298-300.

6. J.S. Reid, Ph.D. Thesis, California Institute of Technology, May, 1995.

7. Phase Diagrams of Ternary Boron Nitride and Silicon Nitride Systems, edited by P. Rogl and J.C. Schuster (ASM International, Materials Park, OH, 1992) pp. 198-202.

\section{DISCLAIMER}

This report was prepared as an account of work sponsored by an agency of the United States Government. Neither the United States Government nor any agency thereof, nor any of their employees, makes any warranty, express or implied, or assumes any legal liability or responsibility for the accuracy, completeness, or usefulness of any information, apparatus, product, or process disclosed, or represents that its use would not infringe privately owned rights. Reference herein to any specific commercial product; process, or service by trade name, trademark, manufacturer, or otherwise does not necessarily constitute or imply its endorsement, recommendation, or favoring by the United States Government or any agency thereof. The views and opinions of authors expressed herein do not necessarily state or reflect those of the United States Government or any agency thereof. 


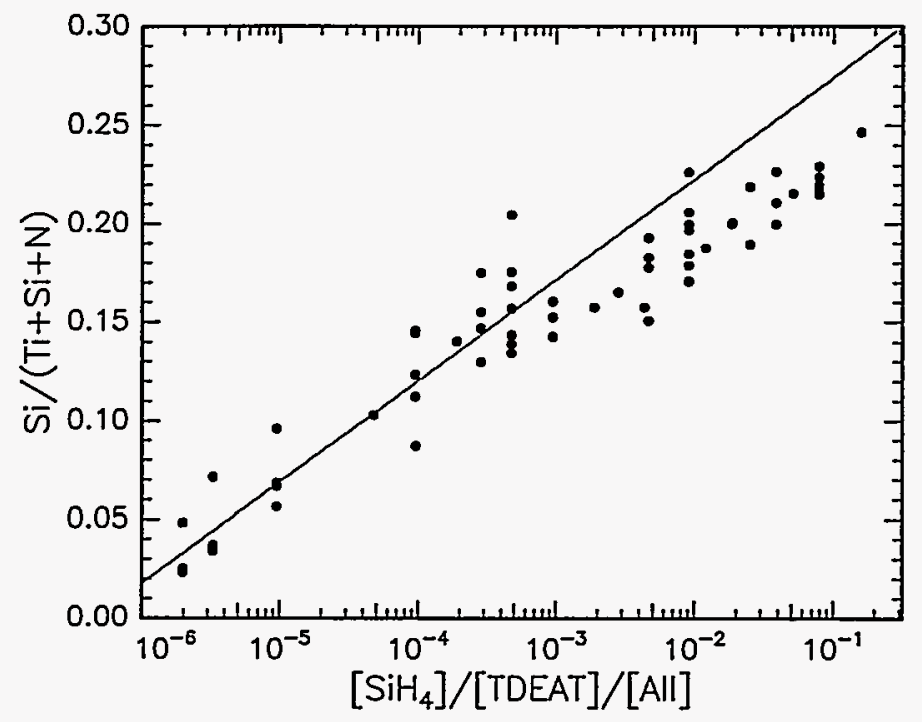

Figure 1. The relative $\mathrm{Si}$ content of films (ignoring $\mathrm{H}$ and $\mathrm{C}$ ) is shown plotted versus the gas flow conditions during the deposition. As the ratio of $\mathrm{SiH}_{4}$ to TDEAT is increased, the $\mathrm{Si}$ content of the film increases logarithmically. All depositions were performed at constant pressure (20 Torr), so the total gas flow ([All]) establishes the residence time in the system. The line is to guide the eye.

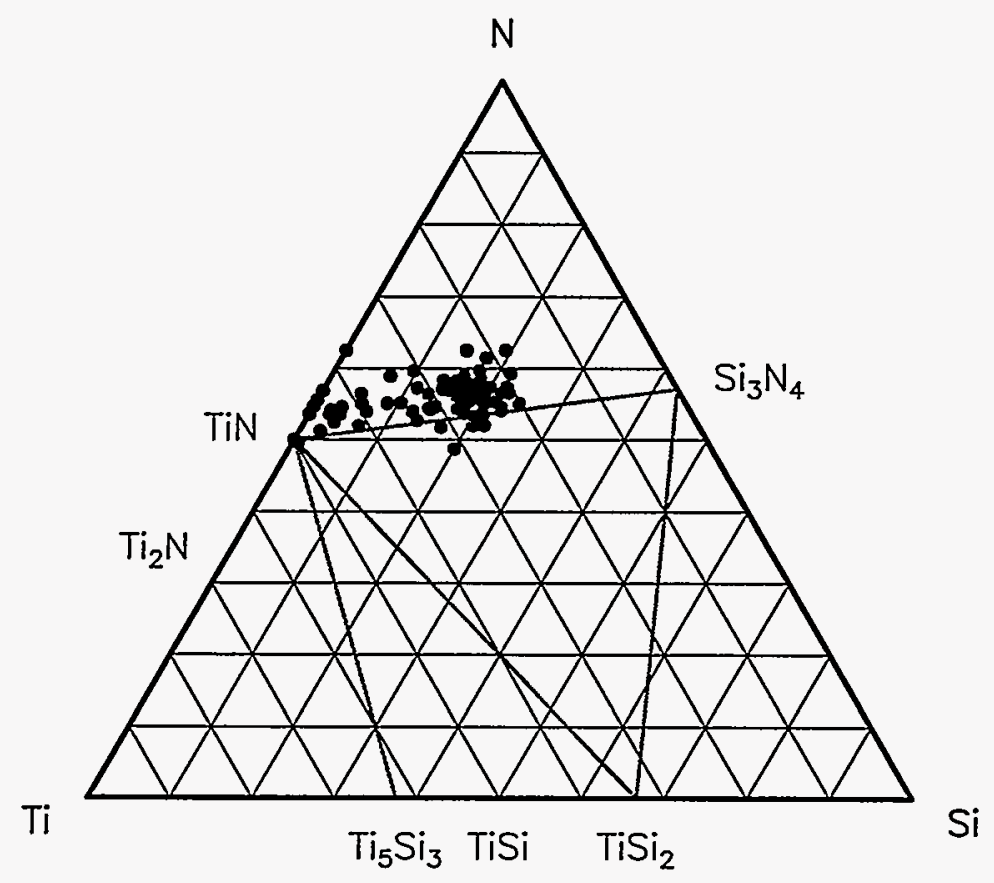

Figure 2. Ternary phase diagram of films produced with the TDEAT/SiH $4 / \mathrm{NH}_{3}$ process at temperatures from 300 to $450^{\circ} \mathrm{C}$. The placement of the points on the phase diagram was determined from the ratios of $\mathrm{Ti}, \mathrm{Si}$, and $\mathrm{N}$ only; the $\mathrm{H}$ and $\mathrm{C}$ contents were ignored. Films deposited at $350^{\circ} \mathrm{C}$ are closest to the tie line, while films at lower and higher temperatures are more $\mathrm{N}$ rich. 


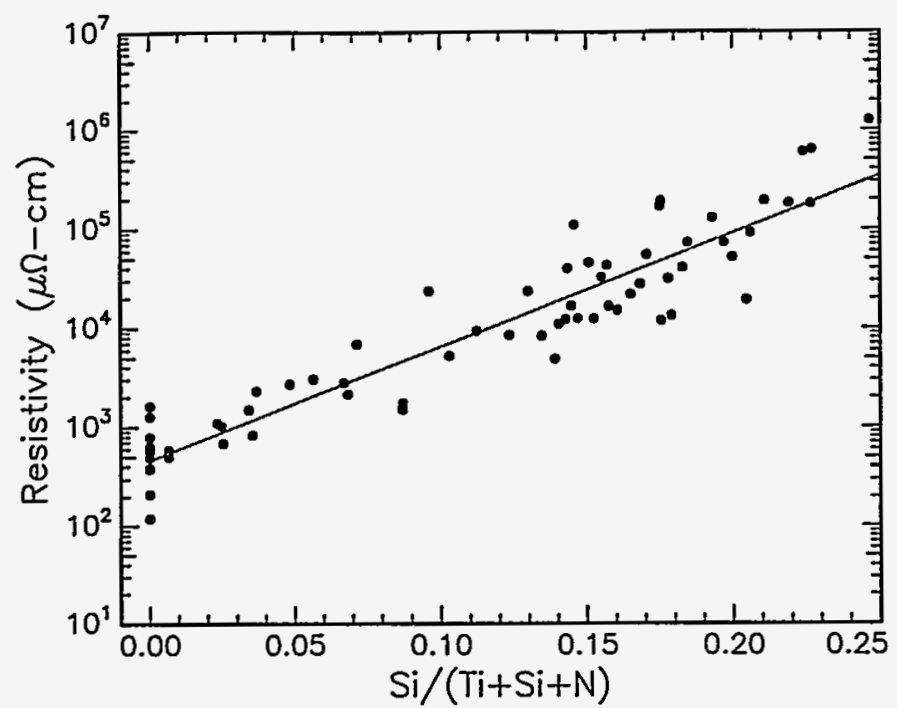

Figure 3. Film resistivity is shown versus the $\mathrm{Si}$ content in the film for films grown at temperatures from 300 to $450^{\circ} \mathrm{C}$. With increasing Si content, the resistivity increases exponentially. Film resistivities below $1000 \mu \Omega$-cm are can be obtained for films with less than 5 at.\% Si. Films grown at $350^{\circ} \mathrm{C}$ have the lowest resistivity at a given Si content. The line is to guide the eye.

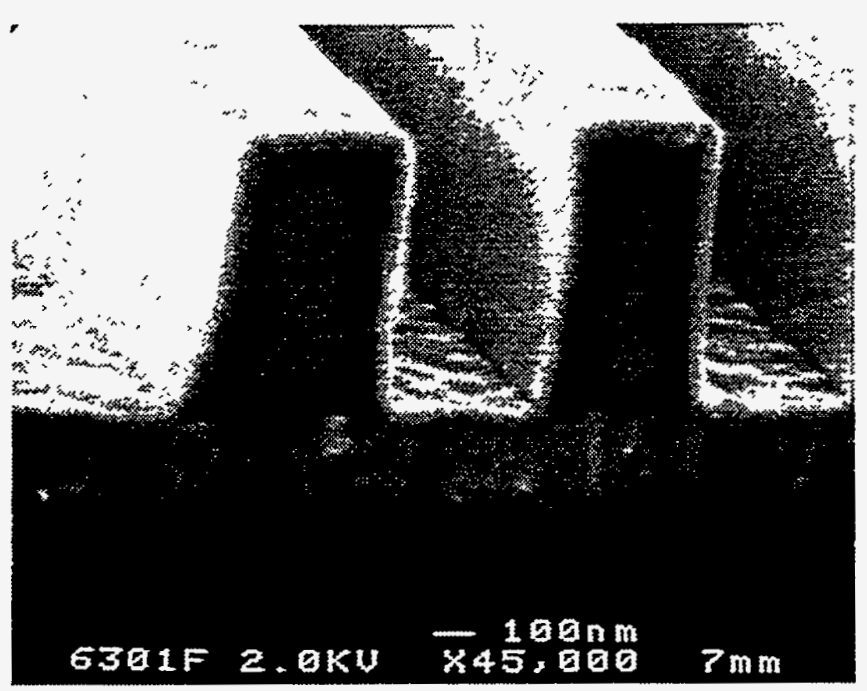

Figure 4. A cross-section $\mathrm{SEM}$ of a $50 \mathrm{~nm}$ thick $\mathrm{Ti}_{46} \mathrm{Si}_{03} \mathrm{~N}_{51}$ film grown at $350^{\circ} \mathrm{C}$, which has a resistivity of under $700 \mu \Omega-\mathrm{cm}$. The film is deposited over $0.5 \mu \mathrm{m}$ lines with an aspect ratio of 1.6 through oxide to polysilicon. The step coverage is at least $80 \%$, and the film faithfully reproduces the irregularities on the original structures. 


\section{DISCLAMEER}

Portions of this document may be illegible in electronic image products. Images are produced from the best available original document. 